\title{
Altered methylation pattern of the SRD5A2 gene in the cerebrospinal fluid of post-finasteride patients: a pilot study
}

\author{
Roberto Cosimo Melcangi ${ }^{1}$, Livio Casarini ${ }^{2,3}$, Marco Marino ${ }^{2,3}$, Daniele Santi ${ }^{2,4}$, Samantha Sperduti ${ }^{2,3}$, Silvia Giatti ${ }^{1}$, \\ Silvia Diviccaro' ${ }^{1}$ Maria Grimoldi ${ }^{5}$, Donatella Caruso ${ }^{1}$, Guido Cavaletti ${ }^{6}$ and Manuela Simoni ${ }^{2,3,4}$ \\ ${ }^{1}$ Dipartimento di Scienze Farmacologiche e Biomolecolari, Università degli Studi di Milano, Milan, Italy \\ 2Unit of Endocrinology, Department of Biomedical, Metabolic and Neural Sciences, University of Modena and Reggio Emilia, Modena, Italy \\ ${ }^{3}$ Center for Genomic Research, University of Modena and Reggio Emilia, Modena, Italy \\ ${ }^{4}$ Department of Medical Specialties, Azienda Ospedaliero-Universitaria di Modena, Modena, Italy \\ ${ }^{5}$ Neurology Division, Papa Giovanni XXIII Hospital, Bergamo, Italy \\ ${ }^{6}$ Experimental Neurology Unit and Milan Center for Neuroscience, School of Medicine and Surgery, University of Milano Bicocca, Monza, Italy
}

Correspondence should be addressed to M Simoni: manuela.simoni@unimore.it

\begin{abstract}
Context: Post-finasteride syndrome (PFS) occurs in patients with androgenic alopecia after suspension of the finasteride treatment, leading to a large variety of persistent side effects. Despite the severity of the clinical picture, the mechanism underlying the PFS symptoms onset and persistence is still unclear.

Objective: To study whether epigenetic modifications occur in PFS patients.

Methods: Retrospective analysis of a multicentric, prospective, longitudinal, case-control clinical trial, enrolling 16 PFS patients, compared to 20 age-matched healthy men. Main outcomes were methylation pattern of SRD5A1 and SRD5A2 promoters and concentration of 11 neuroactive steroids, measured by liquid chromatography-tandem mass spectrometry, in blood and cerebrospinal fluid (CSF) samples. Results: SRD5A1 and SRD5A2 methylation analysis was performed in all blood samples ( $n=16$ PFS patients and $n=20$ controls), in 16 CSF samples from PFS patients and in 13 CSF samples from controls. The SRD5A2 promoter was more frequently methylated in CSF of PFS patients compared to controls (56.3 vs $7.7 \%$ ). No promoter methylation was detected in blood samples in both groups. No methylation occurred in the SRD5A1 promoter of both groups. Unmethylated controls compared to unmethylated SRDSA2 patients showed higher pregnenolone, dihydrotestosterone and dihydroprogesterone, together with lower testosterone CSF levels. Andrological and neurological assessments did not differ between methylated and unmethylated subjects.

Conclusions: For the first time, we demonstrate a tissue-specific methylation pattern of SRD5A2 promoter in PFS patients. Although we cannot conclude whether this pattern is prenatally established or induced by finasteride treatment, it could represent an important mechanism of neuroactive steroid levels and behavioural disturbances previously described in PFS.
\end{abstract}

\author{
Key Words \\ - 5 alpha-reductase \\ - neuroactive steroids \\ - finasteride \\ - side effects \\ - epigenetic changes
}

https://ec.bioscientifica.com

https://doi.org/10.1530/EC-19-0199 (c) 2019 The authors Published by Bioscientifica Ltd

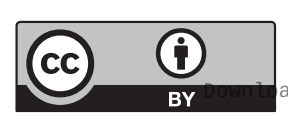

This work is licensed under a Creative Commons Attribution 4.0 International License. ded from Bioscientifica.com at 04/26/2023 12:13:09AM
Endocrine Connections (2019) 8, 1118-1125 


\section{Introduction}

Finasteride is an inhibitor of 5 alpha-reductase ( $5 \alpha-\mathrm{R})$ type 1 and 2 enzymes, encoded by the SRD5A1 and SRD5A2 gene, respectively, with higher affinity for $5 \alpha$-R type 2 in the human $(1,2)$. This enzyme converts testosterone into dihydrotestosterone (DHT) and progesterone into dihydroprogesterone (DHP) (3).

Clinically, finasteride is used to control the progression of benign prostatic hyperplasia and of androgenetic alopecia. Albeit being a well-tolerated and relatively safe drug, recent clinical studies showed sexual adverse effects $(2,4,5,6,7)$. Interestingly, a small subset of patients using finasteride for androgenic alopecia, complains of persistent sexual side effects during and even after discontinuation of the treatment $(2,8,9,10$, $11,12,13,14,15,16,17,18,19,20)$. Beside adverse events in the sexual sphere, some patients interrupting the treatment by finasteride develop depression $(16,17$, $18,20,21,22,23)$, reduction in self-confidence, decreased initiative and difficulty in concentration, forgetfulness or loss of short-term memory, irritability, suicidal thoughts, anxiety, panic attack, sleep problems, muscular stiffness and cramps, tremors, chronic fatigue, joint pain and muscular ache $(18,24,25,26)$. These various symptoms amount to the so-called post-finasteride syndrome (PFS). Two recent clinical studies objectivated impaired sexual function and major depression in PSF patients $(17,18)$. In addition, functional magnetic resonance imaging (MRI) showed abnormalities in the brain regions implicated in depression and regulating sexual arousal (17), and some evidence of neuropathy involving the peripheral neurogenic control of erection was produced (18).

PFS etiopathogenesis remains elusive. Three different clinical studies $(18,25,26)$ demonstrated that finasteride treatment not only affects the steroids directly related with the enzyme $5 \alpha-\mathrm{R}$ but has broad consequences on the levels of several important physiological regulators of the nervous function, such as neuroactive steroids, both in plasma and in cerebrospinal fluid (CSF). These results were confirmed in an animal model of PFS, showing that alterations in the levels of neuroactive steroids not only occurred in plasma and CSF but also in brain areas, such as cerebral cortex, cerebellum and hippocampus (27), associated to depressive-like behaviour, alterations in neurogenesis, gliosis, neuroinflammation and gut microbiota composition (28). A possible hypothesis for the persistent side effects may be epigenetic modifications occurring in PFS patients. Indeed, downregulation and hypermethylation of $5 \alpha-\mathrm{R}$ were observed in the rodent nervous system and associated with inflammation and depression $(29,30)$, features that, as mentioned earlier, have been also observed in PFS model (28). In this setting, the evaluation of the methylation pattern remains challenging since it could change during adulthood and with ageing (31).

In this study, we hypothesised that inappropriate methylation of SRD5A1 and/or SRD5A2 gene promoters could be present in the central nervous system (CNS) of patients with PFS. No studies evaluated so far the methylation levels of these genes in a clinical setting. We compared SRD5A1 and/or SRD5A2 promoter methylation in DNA samples obtained from blood and/or CSF in PFS patients and controls and correlated the resulting epigenetic pattern with the neuroactive steroid levels previously found by us to be associated with major depression and sexual side effects (18).

\section{Materials and methods}

\section{Study design and sample preparation}

Sixteen patients affected by PFS, recruited through the 'Italian network of finasteride side effects', were included in this study. They were otherwise healthy men, aged 22-44 years, who reported persistent sexual and mental health side effects after the use of $1-1.25 \mathrm{mg}$ of finasteride daily (Propecia, Proscar or generic finasteride) for androgenetic alopecia. Only subjects who had discontinued finasteride at least 3 months earlier were included. The study procedure was approved by the Ethics Committee of the San Gerardo Hospital (approval n.142/2012), Monza-Italy and the participating subjects provided their written informed consent before enrolment. This group of PFS patients was previously studied for psychiatric components, andrological assessment and neuroactive steroid levels in plasma and CSF (18).

PFS patients underwent both blood and CSF sampling for SRDA51 and SRDA52 gene promoter methylation analysis. The control group included 18 healthy individuals who underwent spinal anaesthesia for planned orthopaedic surgery of the lower limb at the San Gerardo Hospital of Monza. These subjects were otherwise healthy and never made used of finasteride. After written informed consent, CSF samples were collected. Two subjects of this group provided also a blood sample for DNA analysis. Moreover, the control group included additional 18 age-matched healthy donors, who provided only blood samples for DNA analysis. Control subjects

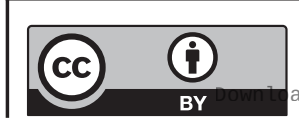

This work is licensed under a Creative Commons Attribution 4.0 International License. 
never used finasteride. The mean age of healthy controls $(40.8 \pm 17.9$ years) was not significantly different from PFS patients ( $34.5 \pm 8.8$ years) $(P=0.192)$.

\section{SRD5A1 and SRD5A2 promoter sequences}

Sequences of SRD5A1 and SRD5A2 gene promoters served for designing primer probes to be used for methylation analysis. SRD5A1 and SRD5A2 promoter sequences were obtained by the online Eukaryotic Promoter Database (EPD; http://epd.vital-it.ch) and correspond to the database ID 'SRD5A1_1' and 'SRD5A2_1', respectively. The SRD5A2 promoter sequence was previously described (32) and matched to that obtained by the EPD, confirming its reliability.

\section{DNA extraction and methylation analysis}

Genomic DNA was isolated from blood and CSF samples by the automated extractor EZ1 Advanced XL (Qiagen) using the EZ1 DNA Blood and the EZ1 DNA Investigator Kits, respectively. We assumed that ependymal cells, of neuroectodermic origin and collected from CSF, are representative of the CNS, providing a source of genomic DNA without resorting to major clinical interventions. Due to the paucity of the cellular component in the CSF, DNA extraction was preliminarily validated, using a kit optimised for forensic purposes, to provide a yield of at least $2.8 \pm 1.1 \mathrm{ng} / \mu \mathrm{L}$ from $4.3 \pm 3.3$ cells $/ \mu \mathrm{L}$ (data obtained from four random, anonymised, sterile CSF validation samples, ranging from 100 to $500 \mu \mathrm{l}$ of total volume).

DNA concentrations and purity were determined by the NanoDrop ${ }^{\text {TM }} 2000$ spectrophotometer (Thermo Fisher Scientific), while the methylation pattern was analysed using the Human Methylated \& Non-methylated DNA Set (Zimo Research, Irvine, CA, USA). Serial dilutions of methylated DNA (0-100\% range), provided by the supplier, were performed to generate the standard curve. Deamination of cytosines was obtained by bisulfite conversion of equal amounts of DNAs using the Methylamp DNA Modification Kit (EpiGentek, Farmingdale, NY, USA) and following the instructions provided by the Company. Quantitative methylation-specific PCR (Q-MSP) was performed for methylation analysis of $\mathrm{CpG}$ islands of SRD5A1 and SRD5A2 promoter regions. The methylation-specific primer pairs were designed by the MethPrimers Software (33) as follows: SRD5A1 forward (Fwd): 5'-AGTTTTATATTTTTCGGGATTTTCG-3' and reverse (Rev): 5'-CGCTTTAAACTTATTCCTAAACGAT-3'; SRD5A2 Fwd: 5'-AAGTTATGGAAGGATAGTTTAAGCG-3' and Rev: 5'-TCTCAAAAATACAACCGCGAT-3'. The methylation-specific primers for the $A C T B$ gene were previously validated (34) and used to provide the internal control. Reactions were performed using the Precision Melt Supermix (Bio-Rad Laboratories Inc.) following the supplier's instructions and following settings: doublestrand DNAs were pre-denatured $2 \mathrm{~min}$ at $95^{\circ} \mathrm{C}$ before 50 cycles of DNA denaturation at $95^{\circ} \mathrm{C}$ for $10 \mathrm{~s}$, each followed by primer binding at $59^{\circ} \mathrm{C}$ for $30 \mathrm{~s}$ and extension at $72^{\circ} \mathrm{C}$ for $30 \mathrm{~s}$. Samples and the standard curve were analysed in duplicate and the percentage of DNA methylation was calculated using the previously described $2^{-\Delta \Delta \mathrm{Ct}}$ method (35) optimised for DNA methylation analyses $(36,37)$. Briefly, $\Delta$ Ct values were calculated by subtracting the internal control Ct value to $\mathrm{Ct}$ of samples and standards. $\Delta \Delta \mathrm{Ct}$ was determined by subtracting the $\Delta \mathrm{Ct}$ of the $100 \%$ methylated DNA standard to the $\Delta \mathrm{Ct}$ of samples and standard dilutions. Standards were plotted on a X-Y graph, where the percentage of methylated DNA is at the $\mathrm{X}$ axis, while the $2^{-\Delta \Delta \mathrm{Ct}}$ value is at the $\mathrm{Y}$ axis. These data were interpolated by linear regression and used for extrapolating the percentage of sample DNA methylation.

\section{Precision of the DNA methylation assay}

Precision of the method was assessed by evaluating the coefficient of variation (\%CV) (38) in relationship to the percentage of methylation. To this purpose, DNA with known percentages of methylation were created by serial dilution as reference standard and the coefficient of variation was calculated as the standard deviation divided by the mean $(\times 100)$.

Cut-off for defining the methylated status was fixed at $10 \%$ and values below this threshold were considered as unmethylated DNA, as previously proposed (39). \%CV of each sample was extrapolated from the reference standard curve and used for evaluating whether it was reliably determined as falling above the methylation cutoff value. All samples are reliably classified as 'methylated' or 'unmethylated', according to the cut-off value fixed at $10 \% \mathrm{CV}$.

\section{Statistical analysis}

Results are expressed as mean \pm s.D. Methylation status of the SRD5A1 and SRD5A2 gene promoters were expressed as percentage of methylated DNA extrapolated from the standard curve.

Kolmogorov-Smirnov test was used to evaluate continuous neuroactive steroid data distribution.

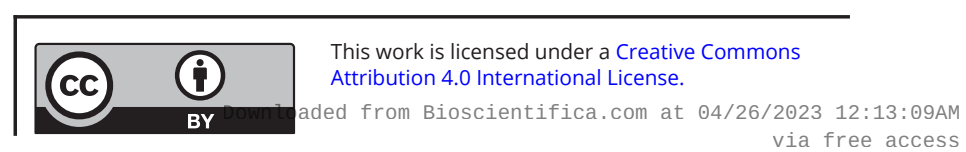


Neuroactive steroid levels in plasma and CSF previously obtained (18) were compared between SRD5A2 unmethylated controls, methylated and unmethylated PFS patients using Kruskall-Wallis test followed by post hoc Dunnet test. The correlation between neuroactive steroid levels and percentage of promoter gene methylation was evaluated using Spearman's Rho test.

The degree of erectile dysfunction and the depressive status of PSF patients was previously reported (18) and was reassessed here by comparing SRD5A2 unmethylated and methylated PFS patients using Pearson's chi-squared test. Similarly, the total score of Beck Depression and Anxiety Inventories (BDI, BAI) and K-10 was compared between patients with and without SRD5A2 methylation, using Mann-Whitney's $U$ test.

Statistics was performed using 'Statistical Package for the Social Sciences' software for Macintosh (version 20.0; SPSS Inc.).

\section{Results}

DNA methylation analysis of SRD5A1 and SRD5A2 was successfully performed in all blood samples $(n=16$ PFS patients and $n=20$ controls), in 16 CSF samples from PFS patients and in 13 CSF samples from controls.

The SRD5A1 gene promoter was completely unmethylated in all samples analysed, irrespective whether blood- or CSF-derived DNA.

Similarly, the SRD5A2 gene promoter resulted unmethylated (i.e. methylation level $<10 \%$ ) in all bloodderived DNA samples, both in controls and in PFS patients. In CSF-derived DNA, the SRD5A2 gene promoter resulted methylated in 9 out of 16 PFS patients and in 1 out of 13 controls $(P=0.006$, Pearson's chi-square test, Table 1$)$. Interestingly, the control subject with positive CSF SRD5A2 methylation was a man affected by normotensive hydrocephalus. In the PFS patients with positive SRD5A2 methylation in CSF, the methylation levels ranged from 15.4 to $100 \%$ (mean: $40.3 \%$, median: $31.8 \%$ ), while the

Table 1 SRD5A2 promoter methylation in DNA extracted from cerebrospinal fluid of PFS patients and controls.

\begin{tabular}{lccccc}
\hline & Controls $(n)$ & & PFS patients $(n)$ & & Total $(n)$ \\
\cline { 1 - 1 } $\begin{array}{l}\text { Unmethylated } \\
\text { SRD5A2 }\end{array}$ & $12(92.3 \%)$ & & $7(43.7 \%)$ & & 19 \\
$\begin{array}{l}\text { Methylated SRD5A2 } \\
\text { Total }(n)\end{array}$ & $1(7.7 \%)$ & & $9(56.3 \%)$ & & 10 \\
\hline
\end{tabular}

Data were evaluated by Pearson's chi-square test, $P<0.01$. unique control sample resulted to be positive to the test showed $58.0 \%$ methylation.

Neuroactive steroid levels in these subjects were reported previously (18). In order to assess whether SRD5A2 methylation affects neuroactive steroid levels, here we compared CSF concentrations in unmethylated controls vs unmethylated and methylated PFS patients (Table 2). Within the limits of the low subject number and of the sensitivity of the LC-MS/MS method for some analytes, the results showed some statistically significant differences (Table 2) indicating higher pregnenolone in unmethylated SRD5A2 controls vs unmethylated SRD5A2 PFS patients. On the contrary, higher testosterone levels were reported in unmethylated SRD5A2 PFS patients vs unmethylated SRD5A2 controls. The $5 \alpha$-reduced metabolites of testosterone and progesterone were also affected. In particular, higher DHT levels were observed in unmethylated SRD5A2 controls vs unmethylated SRD5A2 PFS patients (Table 2). In addition, DHP levels were significantly higher in unmethylated SRDSA2 controls not only vs unmethylated SRD5A2 PSF patients but also vs methylated SRD5A2 PSF patients (Table 2).

In PFS patients, neuroactive steroid CSF levels were not significantly related to the percentage of SRD5A2 gene promoter methylation ( $P>0.05$, Spearman's Rho test).

We next evaluated whether the clinical parameters reported earlier (18) were related to the SRD5A2 methylation status. No differences were observed in the degree of erectile dysfunction $(P=0.362$, Pearson's chisquare test). Accordingly, the five international indexes of erectile function (IIEF-15) domains, identified as erectile function, orgasm, sexual desire, intercourse satisfaction and overall satisfaction, did not differ between groups $(P=0.710, P=0.456, P=0.535, P=0.805$ and $P=0.620$, respectively). Similarly, the depressive status previously demonstrated in these PFS patients (18) did not change between SRD5A2 methylated and unmethylated subjects, considering K-10 $(P=0.890)$ and BDI and BAI $(P=0.475$ and $P=0.485$, respectively). The depression and anxiety degree frequency did not change between two groups ( $P=0.270$ and $P=0.176$, respectively).

\section{Discussion}

In this study, we demonstrate that SRD5A2 promoter methylation in PFS patients is different between tissues of neuroectodermic and mesodermic origin. Although DNA extraction was insufficient in five CSF samples, a significant difference between PFS patients and controls

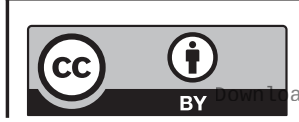

This work is licensed under a Creative Commons Attribution 4.0 International License. ded from Bioscientifica.com at 04/26/2023 12:13:09AM 
Table 2 Neuroactive steroid CSF levels in patients and controls according to the SRD5A2 methylation status.

\begin{tabular}{l}
\hline \\
\hline Pregnenolone \\
Progesterone \\
Dihydroprogesterone \\
Isopregnanolone \\
Tetrahydroprogesterone \\
Dehydroepiandrosterone \\
Testosterone \\
Dihydrotestosterone \\
$3 \alpha$-Diol \\
$3 \beta$-Diol \\
$17 \beta$-Estradiol
\end{tabular}

\begin{tabular}{c}
$\begin{array}{c}\text { Unmethylated SRD5A2 } \\
\text { controls }(n=12)\end{array}$ \\
\hline $0.39 \pm 0.25$ \\
$0.11 \pm 0.14$ \\
$3.07 \pm 1.54$ \\
$0.11 \pm 0.03$ \\
$0.11 \pm 0.03$ \\
$0.29 \pm 0.08$ \\
$0.23 \pm 0.85$ \\
$0.15 \pm 0.12$ \\
$0.05 \pm 0.00^{\#}$ \\
$0.05 \pm 0.00^{\#}$ \\
$0.4 \pm 0.06$
\end{tabular}

\begin{tabular}{c}
$\begin{array}{c}\text { Unmethylated SRD5A2 PFS } \\
\text { patients }(n=7)\end{array}$ \\
\hline $0.09 \pm 0.05^{\mathrm{a}}$ \\
$0.05 \pm 0.01$ \\
$0.25 \pm 0.00^{\mathrm{a}, \mathrm{b}}$ \\
$0.10 \pm 0.00^{\#}$ \\
$0.25 \pm 0.29$ \\
$0.33 \pm 0.05$ \\
$2.53 \pm 2.35^{\mathrm{a}}$ \\
$0.05 \pm 0.01^{\mathrm{a}}$ \\
$0.07 \pm 0.04$ \\
$0.05 \pm 0.00^{\mathrm{b}}$ \\
$0.02 \pm 0.00^{\mathrm{b}}$
\end{tabular}

\begin{tabular}{c}
$\begin{array}{c}\text { Methylated SRD5A2 PFS } \\
\text { patients }(n=9)\end{array}$ \\
\hline $0.31 \pm 0.46$ \\
$0.34 \pm 0.82$ \\
$1.00 \pm 1.28^{\mathrm{a}}$ \\
$0.32 \pm 0.63$ \\
$0.10 \pm 0.00^{\mathrm{b}}$ \\
$0.51 \pm 0.58$ \\
$1.26 \pm 1.48$ \\
$0.49 \pm 1.13$ \\
$0.64 \pm 0.86$ \\
$0.25 \pm 0.57$ \\
$0.22 \pm 0.56$
\end{tabular}

\begin{tabular}{c}
$\boldsymbol{P}$ value \\
\hline $\mathbf{0 . 0 0 8}$ \\
0.111 \\
$\mathbf{0 . 0 0 1}$ \\
0.531 \\
0.275 \\
0.217 \\
$\mathbf{0 . 0 2 8}$ \\
$\mathbf{0 . 0 2 9}$ \\
0.081 \\
0.305 \\
0.676 \\
\hline
\end{tabular}

Neuroactive steroid levels were previously reported (18). Detection limit was $0.1 \mathrm{pg} / \mu \mathrm{L}$ for isopregnanolone and tetrahydroprogesterone, $0.05 \mathrm{pg} / \mu \mathrm{L}$ for progesterone, and $3 \beta$-diol, $0.02 \mathrm{pg} / \mu \mathrm{L}$ for $17 \beta$-estradiol. Data are expressed as $\mathrm{pg} / \mu \mathrm{L}$ (mean \pm s.D.). Data were analysed by Kruskall-Wallis test followed by post hoc Dunnet test ( ${ }^{a}$ vs unmethylated controls, $P<0.05$ ). Bold indicates statistical significance.

${ }^{\mathrm{b}}$ Denotes analytes for which the assay detection limit was used for the statistical analysis.

in SRD5A2 promoter methylation of nervous system (i.e., in CSF) was demonstrated, while no differences were seen for the SRD5A1 gene, which resulted unmethylated in all samples analysed. Interestingly, in PFS patients, SRD5A2 methylation was detected in CSF DNA samples in $56 \%$ of the cases, while it was absent in blood DNA, demonstrating a tissue-specific epigenetic gene silencing. The only CSF sample showing SRD5A2 methylation in controls was detected in one man with normotensive hydrocephalus. Methylation in CSF but not in blood may be not surprising, since methylation is a tissue- and cell-specific process $(40,41,42)$. The low number of cases studied here does not allow definitive conclusions, but we can speculate that PFS primarily affects nervous system via methylation of SRD5A2, which, in turn, may be related to the clinical picture of PFS patients (i.e., major depression and evidence of neuropathy involving the peripheral neurogenic control of erection) $(18,43)$.

In this context, it is important to note that in human prostate, methylation of $S R D 5 A 2$ is regulated by DNA methyltransferase 1 (DNMT1) (44) and that, as demonstrated in animal models, forebrain deletion of DNMT1 (45) or its pharmacological inhibition $(44,46)$ had antidepressant-like properties.

The reason for the persistence of PFS symptoms even long after drug withdrawal in PFS patients remains a mystery. The molecular mechanism of $5 \alpha-\mathrm{R}$ inactivation by finasteride is known since two decades (47), likely resulting in persistent enzymatic inhibition over time $(47,48)$, but this does not fully justify the long-lasting alteration of the neuroactive steroid levels, unless several months/years are required to completely wash-out the drug from the CSF. Assuming that the $5 \alpha-\mathrm{R}$ protein blocked by finasteride cannot become functional again, in this study, we hypothesised that new SRD 5A1 and SRD5A2 transcripts should be produced and new $5 \alpha-\mathrm{R}$ protein should be available once the drug is interrupted, provided the gene promoters are not methylated and silenced. This should be evident from the CSF steroid concentrations in relation to the methylation pattern. Significant changes in neuroactive steroid levels in this group of PFS patients were published earlier, demonstrating a derangement of these levels upstream testosterone production (18). In fact, PFS patients showed higher serum and CSF testosterone levels than healthy controls, while other neuroactive steroids, also including DHT, were suppressed (18). In the present study, the comparison of CSF steroid levels subdividing the patients according to their SRD5A2 methylation status provided some further insights. In unmethylated SRD5A2 PFS patients, we can assume that type $25 \alpha-\mathrm{R}$ is regularly expressed in CNS and finasteride can act on it. Indeed, in these patients the blockade of $5 \alpha-\mathrm{R}$ activity by finasteride results in significant accumulation of testosterone and significant reduction of $5 \alpha$-reduced metabolites DHT and DHP, the latter being even undetectable (Table 2). On the other hand, in methylated SRD5A2 patients, finasteride might act, even if with lower affinity, predominantly or only on the type 1 $5 \alpha-\mathrm{R}$, since SRD5A1 should be expressed. This is suggested by the only partial reduction of DHP, while testosterone and DHT levels were not significantly different from controls. The significant decrease in pregnenolone in SRD5A2 unmethylated PFS patients compared to controls indicate that the blockade of type $25 \alpha$-R activity impacts the very early steps of neurosteroidogenesis as well, although with unknown mechanism.

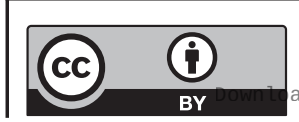


These results, however, must be interpreted with extreme caution, given the low number of subjects analysed. In animal models, it was demonstrated that neurosteroidogenesis may proceed in the brain converting progesterone in DHP and further into tetrahydroprogesterone (THP; allopregnanolone) (3) via a pathway similar to the so-called backdoor pathway of $5 \alpha$-reduction, using type $15 \alpha-\mathrm{R}$ (49). Therefore, the changes in neuroactive steroid levels in CSF of PFS patients demonstrated earlier (18), might be due to inhibition of type $25 \alpha-\mathrm{R}$ only in the subjects with unmethylated $S R D 5 A 2$, while in those with methylated SRD5A2, type $15 \alpha-\mathrm{R}$ could be the target of finasteride. Whether the sexual and psychiatric symptoms documented in these patients are related to methylation of SRD5A2 cannot be concluded by this study, as no significant differences could be demonstrated in dependence thereof, probably due to the low number of subjects.

Presently, it is impossible to establish whether the SRD5A2 methylation pattern in PFS patients is set during early embryo development or results from finasteride treatment itself. DNA methylation is imprinted during gamete production and reprogrammed before embryo implantation (50). Besides the role in determining tissuespecific gene expression, epigenetic mechanisms regulate the individual-specific differentiation of pluripotent stem cells into neurons, suggesting that methylation impacts the pathogenesis of psychiatric disorders (51). Recent findings in rat models confirmed that altered epigenetic processes, consisting in abnormal DNA methyltransferase protein levels and increased global DNA methylation levels, are linked to anxiety- and depression-like behaviour (52). Our finding of high levels of methylated SRD5A2 in CNS cells of a normotensive hydrocephalus individual, displaying an epigenetic status at odds with all other control subjects, further supports the link between DNA methylation pattern and disorders of the nervous system (53). If abnormal SRD5A2 promoter methylation is established prenatally, these subjects could be predisposed to develop the PFS and alteration of neuroactive steroid levels in the brain. In this case, treatment by finasteride might precipitate a dormant depressive phenotype linked to such specific epigenetic pattern, resulting in the clinical picture described previously $(18,43)$. Before finasteride treatment, the impairment of $5 \alpha-\mathrm{R}$ type 2 in the nervous system would be partly compensated by the activity of the $5 \alpha$-R type 1 , found always unmethylated and thereby expressed. On the other hand, the native DNA methylation pattern may change during adulthood and it is susceptible to ageing $(54,55)$, diseases $(56,57,58,59)$, environmental factors and inflammation $(60,61)$. Most importantly, similar effects might be triggered by prolonged exposure to certain drugs, such as amphetamine and methamphetamine (62), inducing behavioural abnormalities. We cannot exclude that some SRD5A2 promoter methylation is determined by finasteride (or other drugs) exposure in adulthood in some subjects developing PFS, although the mechanism of such predisposition remains obscure. Given that epigenetic programming impacts the neuroendocrine response during the adult life (63), we could hypothesise that finasteride impairs DNA methylation targeted to the nervous system, leading to altered neurosteroid CSF levels and leading to major depression and neuropathy described in PFS patients $(18,43)$, but this remains highly speculative.

In conclusion, our results demonstrate methylation of SRD5A2 promoter in a tissue-specific manner in PFS patients. Whether this epigenetic pattern is established prenatally or induced by finasteride treatment cannot be concluded but this study pinpoints the relevance of this specific methylation pattern and its correlation with levels of neuroactive steroids and their effects $(18,43)$. Animal models might be useful to elucidate the link between the use of finasteride, epigenetic changes, neuroactive steroid levels and behavioural disturbances described previously in PFS patients $(27,28)$.

\section{Declaration of interest}

The authors declare that there is no conflict of interest that could be perceived as prejudicing the impartiality of the research reported.

\section{Funding}

The authors thank the Post-Finasteride Foundation for financial support.

\section{References}

1 Finn DA, Beadles-Bohling AS, Beckley EH, Ford MM, Gililland KR, Gorin-Meyer RE \& Wiren KM. A new look at the 5alpha-reductase inhibitor finasteride. CNS Drug Reviews 200612 53-76. (https://doi. org/10.1111/j.1527-3458.2006.00053.x)

2 Traish AM, Melcangi RC, Bortolato M, Garcia-Segura LM \& Zitzmann M. Adverse effects of 5alpha-reductase inhibitors: what do we know, don't know, and need to know? Reviews in Endocrine and Metabolic Disorders 201516 177-198. (https://doi.org/10.1007/ s11154-015-9319-y)

3 Melcangi RC, Garcia-Segura LM \& Mensah-Nyagan AG. Neuroactive steroids: state of the art and new perspectives. Cellular and Molecular Life Sciences 200865 777-797. (https://doi.org/10.1007/s00018-007-7403-5)

4 Nickel JC, Fradet Y, Boake RC, Pommerville PJ, Perreault JP, Afridi SK \& Elhilali MM. Efficacy and safety of finasteride therapy for benign prostatic hyperplasia: results of a 2-year randomized controlled trial (the PROSPECT study). Proscar Safety Plus Efficacy Canadian two year study. Canadian Medical Association Journal 1996155 1251-1259. 
5 Siami P, Roehrborn CG, Barkin J, Damiao R, Wyczolkowski M, Duggan A, Major-Walker K, Morrill BB \& CombAT study group. Combination therapy with dutasteride and tamsulosin in men with moderate-to-severe benign prostatic hyperplasia and prostate enlargement: the CombAT (Combination of Avodart and tamsulosin) trial rationale and study design. Contemporary Clinical Trials $2007 \mathbf{2 8}$ 770-779. (https://doi.org/10.1016/j.cct.2007.07.008)

6 Kaplan SA, Chung DE, Lee RK, Scofield S \& Te AE. A 5-year retrospective analysis of 5alpha-reductase inhibitors in men with benign prostatic hyperplasia: finasteride has comparable urinary symptom efficacy and prostate volume reduction, but less sexual side effects and breast complications than dutasteride. International Journal of Clinical Practice 201266 1052-1055. (https://doi. org/10.1111/j.1742-1241.2012.03010.x

7 La Torre A, Giupponi G, Duffy D, Conca A, Cai T \& Scardigli A Sexual dysfunction related to drugs: a critical review. Part V: alphablocker and 5-ARI drugs. Pharmacopsychiatry 201649 3-13. (https:// doi.org/10.1055/s-0035-1565100)

8 Gur S, Kadowitz PJ \& Hellstrom WJ. Effects of 5-alpha reductase inhibitors on erectile function, sexual desire and ejaculation. Expert Opinion on Drug Safety 201312 81-90. (https://doi.org/10.1517/1474 0338.2013.742885)

9 Corona G, Rastrelli G, Maseroli E, Balercia G, Sforza A, Forti G, Mannucci E \& Maggi M. Inhibitors of 5alpha-reductase-related side effects in patients seeking medical care for sexual dysfunction. Journal of Endocrinological Investigation 201235 915-920. (https://doi. org/10.3275/8510)

10 Traish AM, Hassani J, Guay AT, Zitzmann M \& Hansen ML. Adverse side effects of 5alpha-reductase inhibitors therapy: persistent diminished libido and erectile dysfunction and depression in a subset of patients. Journal of Sexual Medicine 20118 872-884. (https:// doi.org/10.1111/j.1743-6109.2010.02157.x)

11 Irwig MS \& Kolukula S. Persistent sexual side effects of finasteride for male pattern hair loss. Journal of Sexual Medicine 20118 1747-1753. (https://doi.org/10.1111/j.1743-6109.2011.02255.x)

12 Irwig MS. Persistent sexual side effects of finasteride: could they be permanent? Journal of Sexual Medicine 20129 2927-2932. (https:// doi.org/10.1111/j.1743-6109.2012.02846.x)

13 Guo M, Heran B, Flannigan R, Kezouh A \& Etminan M. Persistent sexual dysfunction with finasteride $1 \mathrm{mg}$ taken for hair loss. Pharmacotherapy 201636 1180-1184. (https://doi.org/10.1002/phar.1837)

14 Kiguradze T, Temps WH, Yarnold PR, Cashy J, Brannigan RE, Nardone B, Micali G, West DP \& Belknap SM. Persistent erectile dysfunction in men exposed to the 5alpha-reductase inhibitors, finasteride, or dutasteride. PeerJ 20175 e3020. (https://doi.org/10.7717/peerj.3020)

15 Chiriaco G, Cauci S, Mazzon G \& Trombetta C. An observational retrospective evaluation of 79 young men with long-term adverse effects after use of finasteride against androgenetic alopecia. Andrology 20164 245-250. (https://doi.org/10.1111/andr.12147)

16 Ganzer CA, Jacobs AR \& Iqbal F. Persistent sexual, emotional, and cognitive impairment post-finasteride: a survey of men reporting symptoms. American Journal of Men's Health 20159 222-228. (https:// doi.org/10.1177/1557988314538445)

17 Basaria S, Jasuja R, Huang G, Wharton W, Pan H, Pencina K, Li Z, Travison TG, Bhawan J, Gonthier R, et al. Characteristics of men who report persistent sexual symptoms after finasteride use for hair loss. Journal of Clinical Endocrinology and Metabolism 2016101 4669-4680. (https://doi.org/10.1210/jc.2016-2726)

18 Melcangi RC, Santi D, Spezzano R, Grimoldi M, Tabacchi T, Fusco ML, Diviccaro S, Giatti S, Carra G, Caruso D, et al. Neuroactive steroid levels and psychiatric and andrological features in post-finasteride patients. Journal of Steroid Biochemistry and Molecular Biology 2017171 229-235. (https://doi.org/10.1016/j. jsbmb.2017.04.003)

19 Ali AK, Heran BS \& Etminan M. Persistent sexual dysfunction and suicidal ideation in young men treated with low-dose finasteride: a pharmacovigilance study. Pharmacotherapy 201535 687-695 (https://doi.org/10.1002/phar.1612)

20 Fertig R, Shapiro J, Bergfeld W \& Tosti A. Investigation of the plausibility of 5-alpha-reductase inhibitor syndrome. Skin Appendage Disorders 20172 120-129. (https://doi.org/10.1159/000450617)

21 Irwig MS. Depressive symptoms and suicidal thoughts among former users of finasteride with persistent sexual side effects. Journal of Clinical Psychiatry 201273 1220-1223. (https://doi.org/10.4088/JCP.12m07887)

22 Rahimi-Ardabili B, Pourandarjani R, Habibollahi P \& Mualeki A. Finasteride induced depression: a prospective study. BMC Clinical Pharmacology 2006 6 7. (https://doi.org/10.1186/1472-6904-6-7)

23 Altomare G \& Capella GL. Depression circumstantially related to the administration of finasteride for androgenetic alopecia. Journal of Dermatology 200229 665-669. (https://doi. org/10.1111/j.1346-8138.2002.tb00200.x)

24 Hogan C, Le Noury J, Healy D \& Mangin D. One hundred and twenty cases of enduring sexual dysfunction following treatment. International Journal of Risk and Safety in Medicine 201426 109-116. (https://doi.org/10.3233/JRS-140617)

25 Melcangi RC, Caruso D, Abbiati F, Giatti S, Calabrese D, Piazza F \& Cavaletti G. Neuroactive steroid levels are modified in cerebrospinal fluid and plasma of post-finasteride patients showing persistent sexual side effects and anxious/depressive symptomatology. Journal of Sexual Medicine 201310 2598-2603. (https://doi.org/10.1111/jsm.12269)

26 Caruso D, Abbiati F, Giatti S, Romano S, Fusco L, Cavaletti G \& Melcangi RC. Patients treated for male pattern hair with finasteride show, after discontinuation of the drug, altered levels of neuroactive steroids in cerebrospinal fluid and plasma. Journal of Steroid Biochemistry and Molecular Biology 2015146 74-79. (https://doi. org/10.1016/j.jsbmb.2014.03.012)

27 Giatti S, Foglio B, Romano S, Pesaresi M, Panzica G, GarciaSegura LM, Caruso D \& Melcangi RC. Effects of subchronic finasteride treatment and withdrawal on neuroactive steroid levels and their receptors in the male rat brain. Neuroendocrinology 2016 103 746-757. (https://doi.org/10.1159/000442982)

28 Diviccaro S, Giatti S, Borgo F, Barcella M, Borghi E, Trejo JL, Garcia-Segura LM \& Melcangi RC. Treatment of male rats with finasteride, an inhibitor of 5alpha-reductase enzyme, induces long-lasting effects on depressive-like behavior, hippocampal neurogenesis, neuroinflammation and gut microbiota composition. Psychoneuroendocrinology 201999 206-215. (https://doi. org/10.1016/j.psyneuen.2018.09.021)

29 Araki R, Nishida S, Hiraki Y, Matsumoto K \& Yabe T. DNA methylation of the GC box in the promoter region mediates isolation rearing-induced suppression of srd5a1 transcription in the prefrontal cortex. Neuroscience Letters 2015606 135-139. (https://doi. org/10.1016/j.neulet.2015.08.031)

30 Rossetti MF, Varayoud J, Moreno-Piovano GS, Luque EH \& Ramos JG. Environmental enrichment attenuates the age-related decline in the mRNA expression of steroidogenic enzymes and reduces the methylation state of the steroid 5alpha-reductase type 1 gene in the rat hippocampus. Molecular and Cellular Endocrinology 2015412 330-338. (https://doi.org/10.1016/j.mce.2015.05.024)

31 Harman MF \& Martin MG. Epigenetic mechanisms related to cognitive decline during aging. Journal of Neuroscience Research 2019 [epub]. (https://doi.org/10.1002/jnr.24436)

32 Bechis SK, Otsetov AG, Ge R, Wang Z, Vangel MG, Wu CL, Tabatabaei $S$ \& Olumi AF. Age and obesity promote methylation and suppression of 5alpha-reductase 2: implications for personalized therapy of benign prostatic hyperplasia. Journal of Urology 2015194 1031-1037. (https://doi.org/10.1016/j.juro.2015.04.079)

33 Li LC \& Dahiya R. MethPrimer: designing primers for methylation PCRs. Bioinformatics 200218 1427-1431. (https://doi.org/10.1093/ bioinformatics/18.11.1427)

34 Misawa Y, Misawa K, Kanazawa T, Uehara T, Endo S, Mochizuki D, Yamatodani T, Carey TE \& Mineta H. Tumor suppressor activity

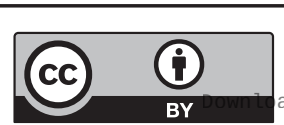

This work is licensed under a Creative Commons Attribution 4.0 International License. ated from Bioscientifica com at $04 / 26 / 2023$ 12:13:09Am 
and inactivation of galanin receptor type 2 by aberrant promoter methylation in head and neck cancer. Cancer 2014120 205-213. (https://doi.org/10.1002/cncr.28411)

35 Livak KJ \& Schmittgen TD. Analysis of relative gene expression data using real-time quantitative PCR and the 2(-Delta Delta C(T)) Method. Methods 200125 402-408. (https://doi.org/10.1006/meth.2001.1262)

36 Dietrich D, Hasinger O, Liebenberg V, Field JK, Kristiansen G \& Soltermann A. DNA methylation of the homeobox genes PITX2 and SHOX2 predicts outcome in non-small-cell lung cancer patients. Diagnostic Molecular Pathology 201221 93-104. (https://doi. org/10.1097/PDM.0b013e318240503b)

37 Vasiljevic N, Ahmad AS, Carter PD, Fisher G, Berney DM, Foster CS, Cuzick J \& Lorincz AT. DNA methylation of PITX2 predicts poor survival in men with prostate cancer. Biomarkers in Medicine $2014 \mathbf{8}$ 1143-1150. (https://doi.org/10.2217/bmm.14.41)

38 Reed GF, Lynn F \& Meade BD. Use of coefficient of variation in assessing variability of quantitative assays. Clinical and Diagnostic Laboratory Immunology 20029 1235-1239. (https://doi.org/10.1128/ cdli.9.6.1235-1239.2002)

39 Ziller MJ, Gu H, Muller F, Donaghey J, Tsai LT, Kohlbacher O, De Jager PL, Rosen ED, Bennett DA, Bernstein BE, et al. Charting a dynamic DNA methylation landscape of the human genome. Nature 2013500 477-481. (https://doi.org/10.1038/nature12433)

40 Devall M, Smith RG, Jeffries A, Hannon E, Davies MN, Schalkwyk L, Mill J, Weedon M \& Lunnon K. Regional differences in mitochondrial DNA methylation in human post-mortem brain tissue. Clinical Epigenetics 20179 47. (https://doi.org/10.1186/s13148-017-0337-3)

41 Zhang B, Zhou Y, Lin N, Lowdon RF, Hong C, Nagarajan RP, Cheng JB, Li D, Stevens M, Lee HJ, et al. Functional DNA methylation differences between tissues, cell types, and across individuals discovered using the M\&M algorithm. Genome Research 201323 1522-1540. (https://doi.org/10.1101/gr.156539.113)

42 Ladd-Acosta C, Pevsner J, Sabunciyan S, Yolken RH, Webster MJ, Dinkins T, Callinan PA, Fan JB, Potash JB \& Feinberg AP. DNA methylation signatures within the human brain. American Journal of Human Genetics 200781 1304-1315. (https://doi.org/10.1086/524110)

43 Giatti S, Diviccaro S, Panzica G \& Melcangi RC. Post-finasteride syndrome and post-SSRI sexual dysfunction: two sides of the same coin? Endocrine 201861 180-193. (https://doi.org/10.1007/s12020018-1593-5)

44 Ge R, Wang Z, Bechis SK, Otsetov AG, Hua S, Wu S, Wu CL, Tabatabaei $S$ \& Olumi AF. DNA methyl transferase 1 reduces expression of SRD5A2 in the aging adult prostate. American Journal of Pathology 2015185 870-882. (https://doi.org/10.1016/j. ajpath.2014.11.020)

45 Morris MJ, Na ES, Autry AE \& Monteggia LM. Impact of DNMT1 and DNMT3a forebrain knockout on depressive- and anxiety like behavior in mice. Neurobiology of Learning and Memory 2016135 139-145. (https://doi.org/10.1016/j.nlm.2016.08.012)

46 Ye D, Zhang L, Fan W, Zhang X \& Dong E. Genipin normalizes depression-like behavior induced by prenatal stress through inhibiting DNMT1. Epigenetics 201813 310-317. (https://doi.org/10. 1080/15592294.2018.1450033)

47 Bull HG, Garcia-Calvo M, Andersson S, Baginsky WF, Chan HK, Ellsworth DE, Miller RR, Stearns RA, Bakshi RK, Rasmusson GH, et al. Mechanism-based inhibition of human steroid $5 \alpha$-reductase by finasteride: enzyme-catalyzed formation of nadp-dihydrofinasteride, a potent bisubstrate analog inhibitor. Journal of the American Chemical Society 1996118 2359-2365.

48 Drury JE, Di Costanzo L, Penning TM \& Christianson DW. Inhibition of human steroid 5beta-reductase (AKR1D1) by finasteride and structure of the enzyme-inhibitor complex. Journal of Biological Chemistry 2009284 19786-19790. (https://doi.org/10.1074/jbc. C109.016931)

49 Miller WL \& Auchus RJ. The molecular biology, biochemistry, and physiology of human steroidogenesis and its disorders. Endocrine Reviews 201132 81-151. (https://doi.org/10.1210/er.2010-0013)

50 Dor Y \& Cedar H. Principles of DNA methylation and their implications for biology and medicine. Lancet 2018392 777-786. (https://doi.org/10.1016/S0140-6736(18)31268-6)

51 Lewis EM \& Kroll KL. Development and disease in a dish: the epigenetics of neurodevelopmental disorders. Epigenomics $2018 \mathbf{1 0}$ 219-231. (https://doi.org/10.2217/epi-2017-0113)

52 McCoy CR, Glover ME, Flynn LT, Simmons RK, Cohen JL, Ptacek T, Lefkowitz EJ, Jackson NL, Akil H, Wu X, et al. Altered DNA methylation in the developing brains of rats genetically prone to high versus low anxiety. Journal of Neuroscience 201939 3144-3158. (https://doi.org/10.1523/JNEUROSCI.1157-15.2019)

53 Qureshi IA \& Mehler MF. Epigenetic mechanisms underlying nervous system diseases. Handbook of Clinical Neurology 2018147 43-58. (https://doi.org/10.1016/B978-0-444-63233-3.00005-1)

54 Maegawa S, Hinkal G, Kim HS, Shen L, Zhang L, Zhang J, Zhang N, Liang S, Donehower LA \& Issa JP. Widespread and tissue specific agerelated DNA methylation changes in mice. Genome Research 201020 332-340. (https://doi.org/10.1101/gr.096826.109)

55 Nejman D, Straussman R, Steinfeld I, Ruvolo M, Roberts D, Yakhini Z \& Cedar H. Molecular rules governing de novo methylation in cancer. Cancer Research 201474 1475-1483. (https://doi. org/10.1158/0008-5472.CAN-13-3042)

56 Zhang J, Wang C, Chen M, Cao J, Zhong Y, Chen L, Shen HM $\&$ Xia D. Epigenetic silencing of glutaminase 2 in human liver and colon cancers. BMC Cancer 201313 601. (https://doi. org/10.1186/1471-2407-13-601)

57 Elhamamsy AR. Role of DNA methylation in imprinting disorders: an updated review. Journal of Assisted Reproduction and Genetics 201734 549-562. (https://doi.org/10.1007/s10815-017-0895-5)

58 Horsthemke B. In brief: genomic imprinting and imprinting diseases. Journal of Pathology 2014232 485-487. (https://doi.org/10.1002/ path.4326)

59 Liu XS, Wu H, Krzisch M, Wu X, Graef J, Muffat J, Hnisz D, Li CH, Yuan B, Xu C, et al. Rescue of fragile X syndrome neurons by DNA methylation editing of the FMR1 gene. Cell 2018172 979.e6-992.e6. (https://doi.org/10.1016/j.cell.2018.01.012)

60 Abu-Remaileh M, Bender S, Raddatz G, Ansari I, Cohen D, Gutekunst J, Musch T, Linhart H, Breiling A, Pikarsky E, et al. Chronic inflammation induces a novel epigenetic program that is conserved in intestinal adenomas and in colorectal cancer. Cancer Research 201575 2120-2130. (https://doi.org/10.1158/0008-5472. CAN-14-3295)

61 Hodjat M, Rahmani S, Khan F, Niaz K, Navaei-Nigjeh M, Mohammadi Nejad S \& Abdollahi M. Environmental toxicants, incidence of degenerative diseases, and therapies from the epigenetic point of view. Archives of Toxicology 201791 2577-2597. (https://doi. org/10.1007/s00204-017-1979-9)

62 Godino A, Jayanthi S \& Cadet JL. Epigenetic landscape of amphetamine and methamphetamine addiction in rodents. Epigenetics 201510 574-580. (https://doi.org/10.1080/15592294.201 5.1055441)

63 Dirven BCJ, Homberg JR, Kozicz T \& Henckens MJAG. Epigenetic programming of the neuroendocrine stress response by adult life stress. Journal of Molecular Endocrinology 201759 R11-R31. (https:// doi.org/10.1530/JME-17-0019)

Received in final form 10 June 2019

Accepted 4 July 2019

Accepted Preprint published online 4 July 2019 https://ec.bioscientifica.com https://doi.org/10.1530/EC-19-0199 (c) 2019 The authors Published by Bioscientifica Ltd

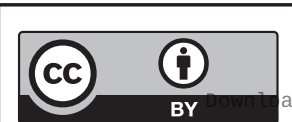

This work is licensed under a Creative Commons Attribution 4.0 International License. ed from Bioscientifica com at 04/26/2023 12:13:09AM 